\title{
A Mathematical Model for Parametric Tooth Profile of Spur Gears
}

\author{
Guodong Zhai $\mathbb{D}^{1},{ }^{1}$ Zhihao Liang, ${ }^{1}$ and Zihao $\mathrm{Fu}^{2}$ \\ ${ }^{1}$ School of Mechanical Electronic \& Information Engineering, China University of Mining and Technology (Beijing), \\ Beijing 100083, China \\ ${ }^{2}$ School of Aeronautic Science and Engineering, Beihang University, Beijing 100083, China \\ Correspondence should be addressed to Guodong Zhai; zgd@cumtb.edu.cn
}

Received 6 September 2019; Revised 25 December 2019; Accepted 18 January 2020; Published 24 February 2020

Academic Editor: Giuseppe Vairo

Copyright ( 2020 Guodong Zhai et al. This is an open access article distributed under the Creative Commons Attribution License, which permits unrestricted use, distribution, and reproduction in any medium, provided the original work is properly cited.

\begin{abstract}
Spur gears are widely used transmission components. In the traditional design process, the noninvolute part of the tooth profile curve is difficult to describe with mathematical equations. This article puts forward a new parametric modeling method, which can describe the modified involute part of spur gears and parameterize and optimize the transition part of the involute curve of the spur gear. And this model of the spur gear can be created by parameters which is input in Scilab software and the spur gear graphic can be completed correspondingly. The experiments show that this modeling method can more quickly produce the standard spur or modified spur gear, and it also improves the efficiency and accuracy of spur gear modeling.
\end{abstract}

\section{Introduction}

A gear or cogwheel is a rotating machine part with cut teeth or cogs, which mesh with another toothed part to transmit torque. Gears always produce a change in torque, creating a mechanical advantage through their gear transmit ratio. So, it may be considered a simple machine. The spur gear is a cylindrical shaped gear in which the teeth are parallel to the axis, as shown in Figure 1. The parallel axis gears have the highest efficiency among all categories of the gear. The spur gear is a standard component and has the largest applications. They are excellent at moderate speeds and can easily achieve a constant drive ratio.

Zhu et al. [1] took a harmonic gear with circular arc profile as the research object, calculated the flexspline profile curve when loaded with the elliptic cam wave generator. Liang et al. [2] used penalty function to solve the mathematical model aiming at the minimum volume and transmission noise of the spiral bevel gear. Spitas and Spitas [3] proposed a nonstandard optimal design scheme to replace involute gears. By setting objective functions and constraints, the fillet stress of gears was reduced [3]. Jia et al. [4] combined load-bearing contact analysis (LTCA) with intelligent optimization algorithm to establish an optimization model. By using Lingo and metaheuristic algorithm, Padmanabhan et al. [5] optimized the bevel gear pair by setting the objective function. The effectiveness of the algorithm is verified by the gear design problem, and the comparison results are studied [5]. Sanchez et al. [6] studied the contact condition of tooth profile modification under load and explained the influence of tooth profile modification on the transmission error. Litvin and Fuentes [7] introduced the design of modern gear drive and the computer simulation of meshing contact of all kinds of gears and analyzed the theory of modern gear drive and the geometry knowledge of design and manufacture of all kinds of gear drive. The research provided a general method to generate profiles also for worm gears [7]. Zelený et al. [8] introduced the mathematical models of helical and spur gears. Yuan et al. [9] introduced the genetic algorithm to minimize the transmission error fluctuation of gears and optimized the gear modification parameters. Fan and Zhang [10] used the finite element method to establish the mathematical model of tooth shape optimization of double involute gear. Guo et al. [11] used finite element analysis technology to optimize the shape of the gear transition curve. Tian et al. [12] used geometric error compensation to reconstruct the geometric model of the tooth profile. 


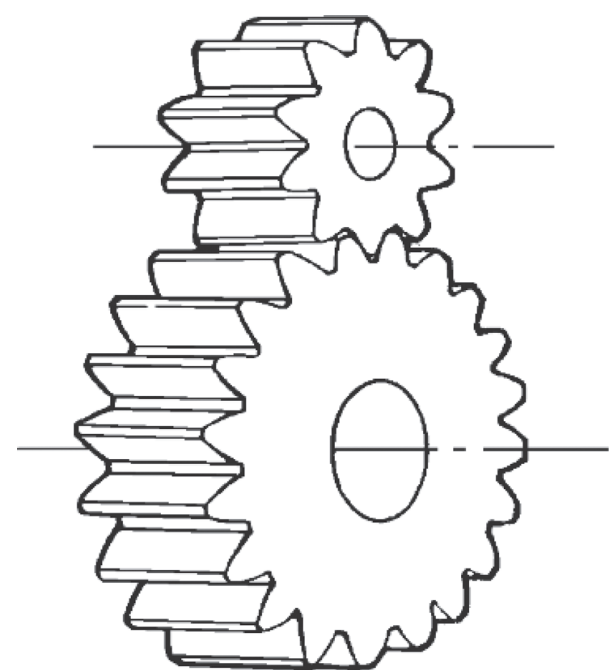

Figure 1: Spur gear.

Figliolini et al. [13] proposed that the contact profile of involute teeth of spur and bevel gears could be obtained by using plane or corresponding spherical helix as auxiliary center of mass. Ma et al. [14] deduced the tooth surface equation of the gear by using the space meshing theory and realized the optimal design of the gear.

Parametric modeling is a process based on algorithm that enables the expression of parameters and rules that, together, define, encode, and clarify the relationship between design intent and design response [15]. And parametric modeling is a paradigm in designing and expressing the relationship between elements which is used to manipulate and inform the design of complex geometries and structures. The parameter modeling method is used extensively in all design software, and it makes the designing work more effective and convenient [16]. Currently, there are two main methods to create a parametric model of the spur gear. One method, for two-dimensional plane, is parametric relation. Another method, for three-dimensional plane, is geometric modeling. It means that the spur gear model is obtained by modules in some modeling software, such as SolidWorks.

With the development of computer simulation modeling technology, SolidWorks, UG, Pro/E, and other three-dimensional parametric software have appeared in gear precise modeling [17-20]. In the analysis of the three-dimensional modeling data of gears, there are ANSYS, Coro, MATLAB, and other analysis software [21-23]. Dolen et al. [24] used the genetic algorithm to optimize the design of the fourstage gear train by setting objective function. Five different genetic coding schemes were proposed for optimum design conditions [24]. Wang et al. [25] optimized the three-dimensional model of the internal gear by establishing the mathematical models of the top and root profile equation and the modified equation. Lin et al. [26] used the combined mutation differential evolution algorithm to engage the involute tooth profile with full-depth displacement. Spitas et al. [27] solved the problem of gear stress minimization by using the concept of dimensionless gear teeth. This method effectively reduced the number of design variables and calculation time [27].
Liang et al. [28] improved the durability of the involute helical gear by establishing the mathematical model of the involute hobbing cutter. Wang et al. [29] optimized the profile modification of the end face of gear teeth by deducing the tooth surface equation of the rack cutter. From the angle of gear processing, Feng et al. [30] took the whole tooth surface of the gear as the envelope of the imaginary gear shaping cutter tooth surface family and then determined the maximum radius of the face gear.

Usually the parameter modeling for the spur gear for the two-dimensional plane is a complex mathematics and programming project, which should be considered by many factors. Most of the mathematics model only define how to represent the valid expression to create the spur gear and try to validate the expression right or not. They do not consider the curve in the noninvolute profile of the spur gear and the optimization in the noninvolute profile. This article mainly focuses on the curve in the noninvolute profile of the spur gear and the optimization in the noninvolute profile. After completing the modeling of a portion of the tooth profile, the entire tooth profile can be accomplished by using a circular array.

\section{Spur Gear Design Fundamentals}

To design a spur gear, it is needed to create a tooth profile of the spur gear. To design a tooth profile of the spur gear, the first step is to know the components of the spur gear's tooth profile. The stereogram of the tooth profile is shown in Figure 2.

In all tooth profiles, the involute curve is the most commonly used. The plain of the tooth profile is shown in Figure 3. The tooth profile of spur gears is composed of involute and noninvolute tooth profiles. So, by means of parameter modeling, the one tooth profile with the involute curve can be built. The rotation matrix will be used to create a whole spur gear until one tooth profile is completed.

The spur gears are a very common component. The fundamental functions about the spur gear are the key to parametric modeling.

2.1. The Tooth Thickness Function. In order to get the expression of the involute profile, the thickness of circular teeth should be calculated first. The base circle is an imaginary circle on the involute cylindrical gear. When the generating line forming the involute profile (or the generating circle forming the cycloid profile) rolls purely on the circumference of the imaginary circle, the imaginary circle is the base circle. Figure 4 shows the transfer of tooth thickness to the base circle. For any radius of the circle, equation (1) can get the value of corresponding tooth thickness:

$$
\begin{aligned}
S_{\mathrm{ty}} & =d_{\mathrm{y}}\left(\frac{S_{\text {tref }}}{d_{\text {ref }}}+\operatorname{inv} \alpha_{\mathrm{t}}-\operatorname{inv} \alpha_{\mathrm{y}}\right), \\
\cos \alpha_{y} & =\frac{r_{b}}{r_{y}},
\end{aligned}
$$




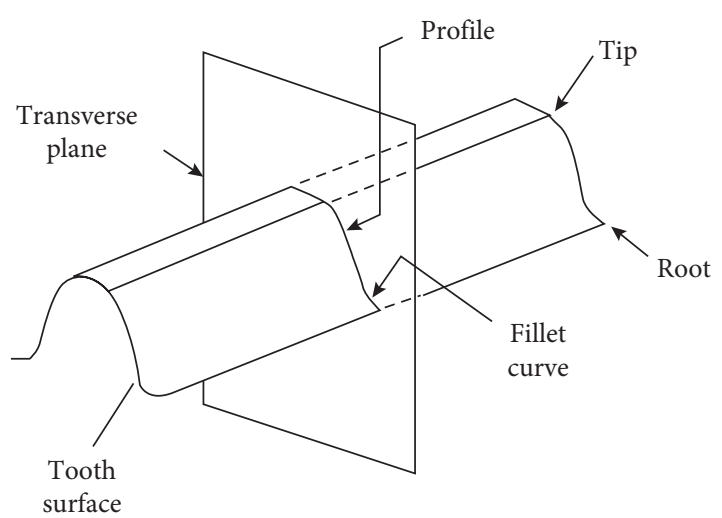

FIGURE 2: The stereogram of the tooth profile.

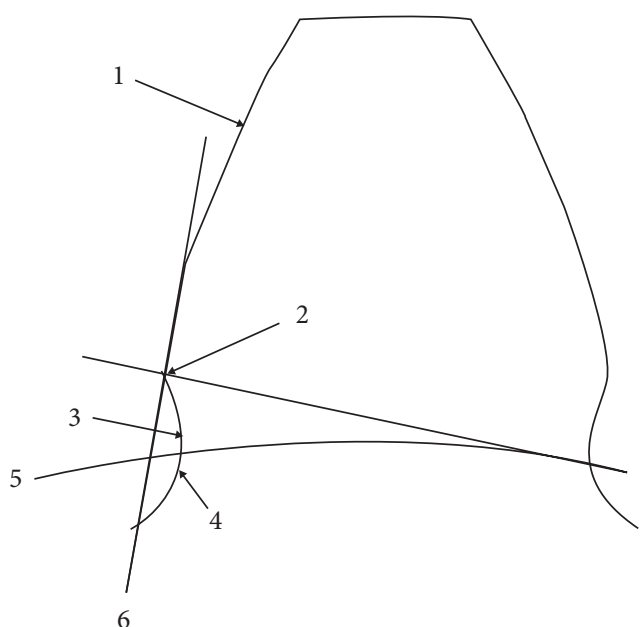

Figure 3: The plain of the tooth profile with involute curve. (1) Working profile; (2) lowest point of the working profile on which contact may occur; (3) undercut; (4) fillet curve; (5) base circle; (6) tangent at lowest point of working profile.

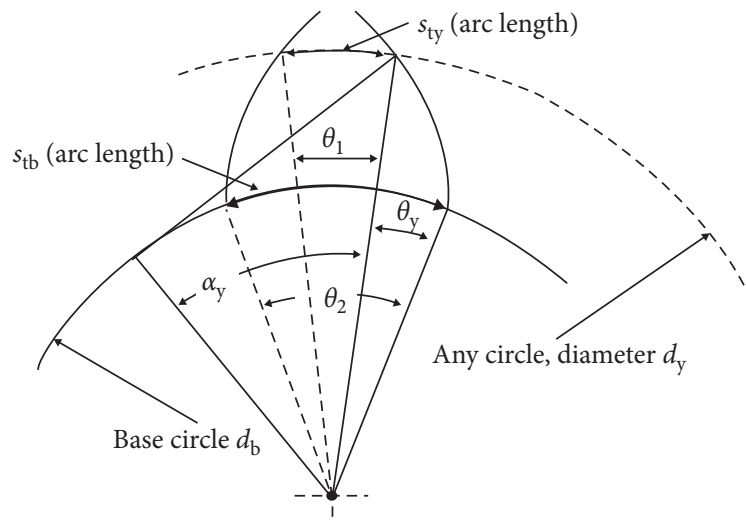

FIgURE 4: Transfer of tooth thickness to the base circle.

$$
d_{y}=2 r_{y}
$$

where $S_{\text {ty }}$ is tooth thickness in any circle, $d_{\mathrm{y}}$ is the diameter of any circle, $S_{\text {tref }}$ is tooth thickness of the reference circle, $d_{\text {ref }}$ is the diameter of the reference circle, $\alpha_{\mathrm{t}}$ is the pressure angle, $\alpha_{\mathrm{y}}$ is the pressure angle in any circle, $r_{\mathrm{b}}$ is the radius of the base circle, and $r_{\mathrm{y}}$ is the radius of any circle.

The variable can be thought as $r_{\mathrm{y}}$ and the tooth thickness can be easily deduced from the function. After that, it will represent the involute profile part.

2.2. The Involute Function. Figure 5 shows an element of the involute curve. The definition of the involute curve is the curve traced by a point on a straight line that rolls without slipping on the circle. The circle is called the base circle of the involutes. Two opposite hand involute curves meeting at a cusp form a gear tooth curve. From Figure 5, the length of base circle arc ac equals the length of the straight line bc:

$$
\begin{aligned}
& \tan \alpha_{\mathrm{t}}=\frac{\mathrm{bc}}{\mathrm{oc}}=\frac{r_{\mathrm{b}} \theta}{r_{\mathrm{b}}}=\theta=\frac{\pi}{9}, \\
& \operatorname{inv} \alpha_{\mathrm{y}}=\tan \alpha-\alpha,
\end{aligned}
$$

where $\alpha_{\mathrm{t}}$ is the pressure angle and $\alpha_{\mathrm{y}}$ is the pressure angle in any circle.

Function of $\alpha$, or $\operatorname{inv} \alpha$, is known as involute function. Involute function is very important in the gear design. The relation of $r_{\mathrm{y}}$ and $S_{\text {ty }}$ can be deduced by the involute function:

$$
\begin{aligned}
S_{\mathrm{ty}}= & r_{\mathrm{y}} \cdot\left[\frac{\pi}{z}-2 \tan \left(\arccos \frac{\operatorname{mzcos}\left(\alpha_{\mathrm{t}}\right)}{2 r_{\mathrm{y}}}\right)+2 \arccos \frac{\operatorname{mzcos}\left(\alpha_{\mathrm{t}}\right)}{2 r_{\mathrm{y}}}\right. \\
& \left.+2 \tan \alpha_{\mathrm{t}}-2 \alpha_{\mathrm{t}}\right],
\end{aligned}
$$

where $m$ is the module of gear and $z$ is the number of teeth of gear.

\section{Process of Parametric Modeling}

3.1. Choose the Coordinate System. First of all, what is the important thing is to find the appropriate coordinate system of the tooth profile. So, it is assumed that the origin is the center of the pitch circle. According to this coordinate system, the next step is to create the module of one tooth that is, $y$ axial symmetry in the tooth profile. In Figure 6 , the center of the gear pitch circle is located at the origin $(0,0)$ of the coordinate system. In order to show the axis of symmetry of a tooth profile, we use the vertical dotted line for identification. To complete the presentation of a gear tooth, the dotted line in the middle of the image is part of the tooth root circle. The coordinate system is shown in Figure 6.

3.2. Create the Involute Profile. The method is determined to generate the profile of a gear as a set of $(x, y)$ coordinates, from basic data (module, number of teeth, etc.).

With the tooth thickness equation, it helps to generate the profile of a gear as a set of $(x, y)$. As shown in Figure 6 , the $y$-axis passes through the center of the circle and bisects one tooth. Due to the equation, the arc can be computed: 


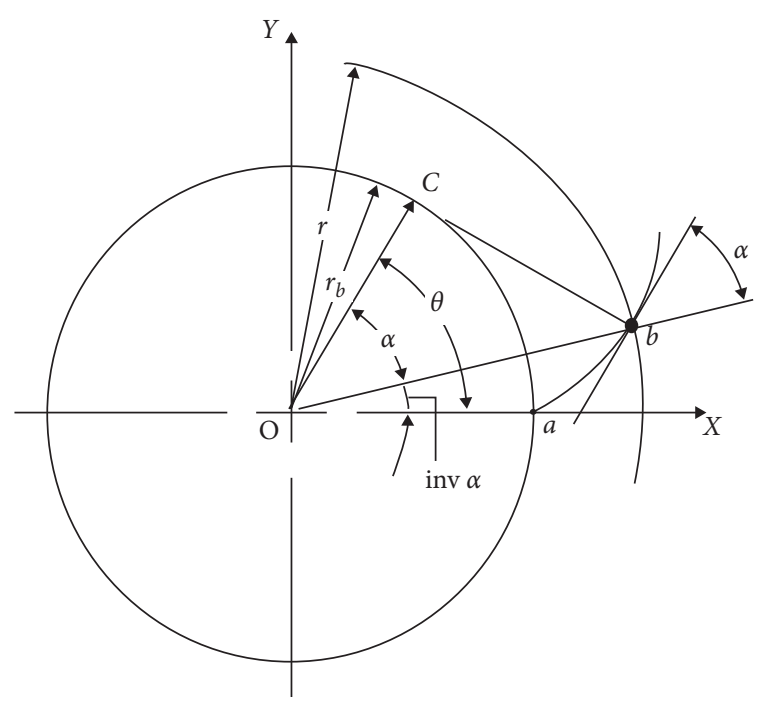

FIgURE 5: Involute curve.

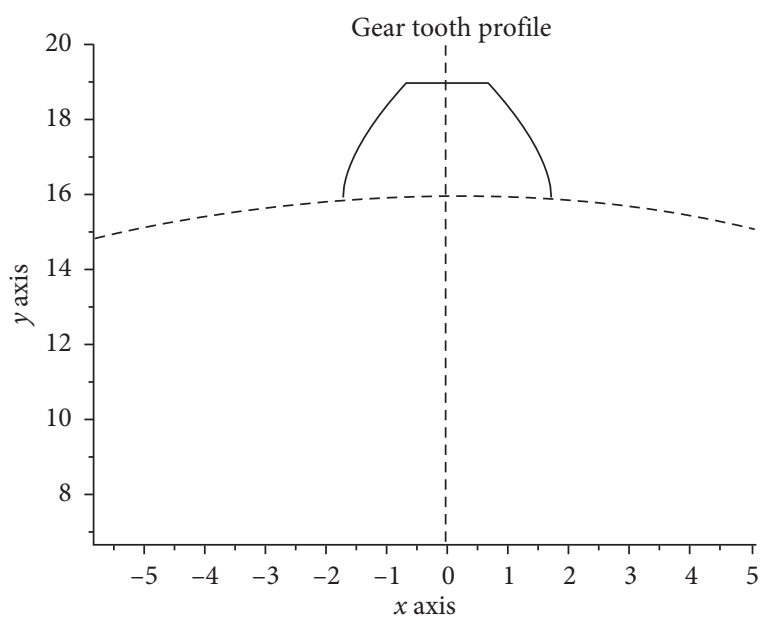

Figure 6: The coordinate system.

$$
\begin{aligned}
\theta_{1} & =\frac{s_{\text {ty }}}{r_{\mathrm{y}}} \\
S_{\text {ty }} & =r_{\mathrm{y}} \cdot\left[\frac{\pi}{z}+2\left(\tan \alpha_{\mathrm{t}}-\alpha_{\mathrm{t}}\right)-2\left(\tan \alpha_{\mathrm{y}}-\alpha_{\mathrm{y}}\right)\right] .
\end{aligned}
$$

According to the abovementioned equations, $r_{\mathrm{y}}$ is assumed as the variable. Hence, the one tooth's tooth profile is represented:

$$
\begin{aligned}
& x=r_{\mathrm{y}} \cdot \sin \frac{\theta_{1}}{2}, \\
& y=r_{\mathrm{y}} \cdot \cos \frac{\theta_{1}}{2} \\
& x=r_{\mathrm{y}} \cdot \sin \left(\frac{\pi}{2 z}+\tan \alpha_{\mathrm{t}}-\alpha_{\mathrm{t}}-\tan \alpha_{\mathrm{y}}+\alpha_{\mathrm{y}}\right), \\
& y=r_{\mathrm{y}} \cdot \cos \left(\frac{\pi}{2 z}+\tan \alpha_{\mathrm{t}}-\alpha_{\mathrm{t}}-\tan \alpha_{\mathrm{y}}+\alpha_{\mathrm{y}}\right) .
\end{aligned}
$$

After computing this program, we can get the tooth profile (above the base circle) expect the top land. The tooth profile is shown in Figure 7. But these four equations cannot represent the whole tooth profile. These can only represent the tooth profile above the base circle.

Figure 8 shows the top land. These equations cannot represent the top land, and the variable $r_{\mathrm{y}}$ has a limiting condition.

The next step is creating the module of the top land. Because the generating method is the common method in manufacturing the spur gear, so the graph of the top land can be thought as an arc whose radius is $r_{\mathrm{a}}$ :

$$
x^{2}+y^{2}=r_{\mathrm{a}}^{2},
$$

where $r_{\mathrm{a}}$ is the radius of the top circle:

$$
r_{\mathrm{a}}=m \cdot z+2 m
$$

In Scilab, $X$ is a variable. So, the programming idea is that the last point in the involute curve is the start point in the top land curve. Then, use formula (11) to express the $\mathrm{Y}$ value with $X$ and plot. The whole tooth profile is shown in Figure 9.

3.3. Create the Noninvolute Profile. The difference between Figures 10 and 11 is the link from the tooth profile above the base circle to the tooth profile below the base circle. So, the key point is to make sure that the end point from the tooth profile above the base circle has the same common tangent with the start point from the tooth profile below the base circle.

The analysis of the arc is shown in Figure 12. When manufacturing the spur gear by laser cutting, the transition section from the involute curve to the noninvolute curve will be destroyed if they do not have the same common tangent. To create the part below the base circle, the first step is to assume the shape of this part. Figure 12 shows that the next step is to create parts under the base circle by finding the boundary of the same common tangent on the profile curve, that is, the position where the base circle curve intersects the profile curve.

When the generating method is used to manufacture the spur gear, the rack cutter's pitch line rolling on a pitch circle generates a spur gear. The generating method is shown in Figure 13. It is easy to find the shape of the tooth profile's part below the base circle which looks like the circle arc.

And the next step is to know some basic parameters about this circle arc, such as the origin of this circle arc, the radius of this circle arc, and the radian from the start to the end of this circle arc.

Firstly, get the common tangency's slope. With the value slope, the next step is to obtain the negative inverse slope.

Because the link point is the point where $r_{\mathrm{y}}=r_{\mathrm{b}}$. So, it can be obtained the derivative at the link point:

$$
\begin{aligned}
& \frac{d_{x}}{d_{r_{\mathrm{y}}}}=\frac{d\left[r_{\mathrm{y}} \cdot \sin \left((\pi / 2 z)+\tan \alpha_{\mathrm{t}}-\alpha_{\mathrm{t}}-\tan \alpha_{\mathrm{y}}+\alpha_{\mathrm{y}}\right)\right]}{d_{r \mathrm{y}}}, \\
& \frac{d_{y}}{d_{r_{\mathrm{y}}}}=\frac{d\left[r_{\mathrm{y}} \cdot \cos \left((\pi / 2 z)+\tan \alpha_{\mathrm{t}}-\alpha_{\mathrm{t}}-\tan \alpha_{\mathrm{y}}+\alpha_{\mathrm{y}}\right)\right]}{d_{\mathrm{ry}}} .
\end{aligned}
$$




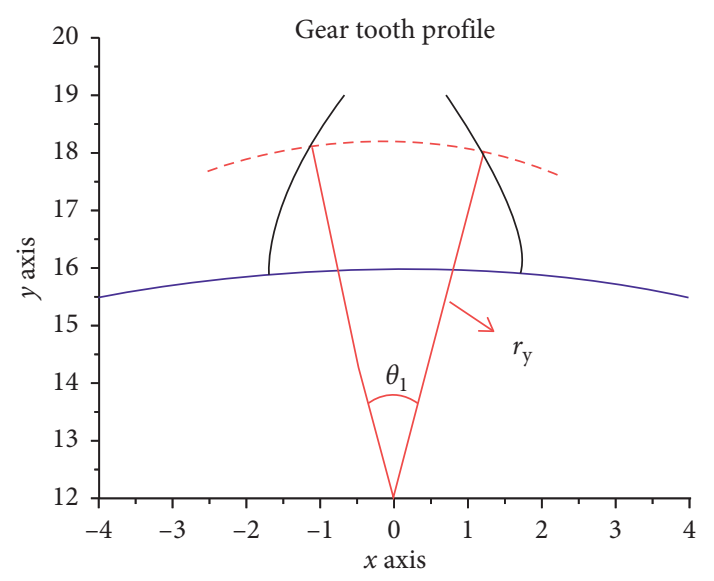

FIgURE 7: The tooth profile.

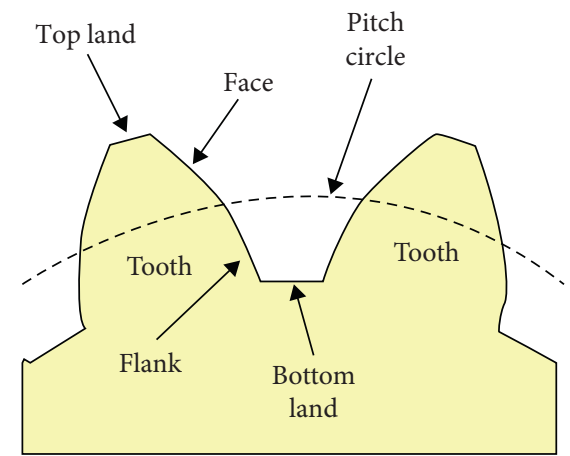

Figure 8: Top land.

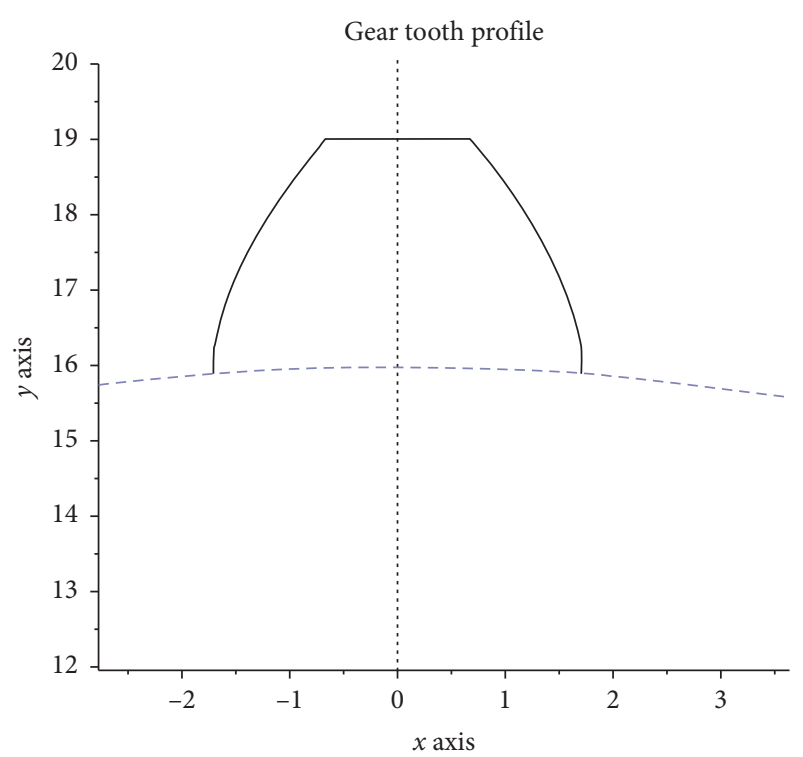

FIgURE 9: The whole tooth profile.

In this condition, $r_{\mathrm{y}}=r_{\mathrm{b}}$ :

$$
\begin{aligned}
& k=\frac{d_{y}}{d_{x}}, \\
& k=\frac{\cos \left((\pi / 2 z)+\tan \alpha_{\mathrm{t}}-\alpha_{\mathrm{t}}-\tan \alpha_{\mathrm{y}}+\alpha_{\mathrm{y}}\right)}{\sin \left((\pi / 2 z)+\tan \alpha_{\mathrm{t}}-\alpha_{\mathrm{t}}-\tan \alpha_{\mathrm{y}}+\alpha_{\mathrm{y}}\right)} .
\end{aligned}
$$

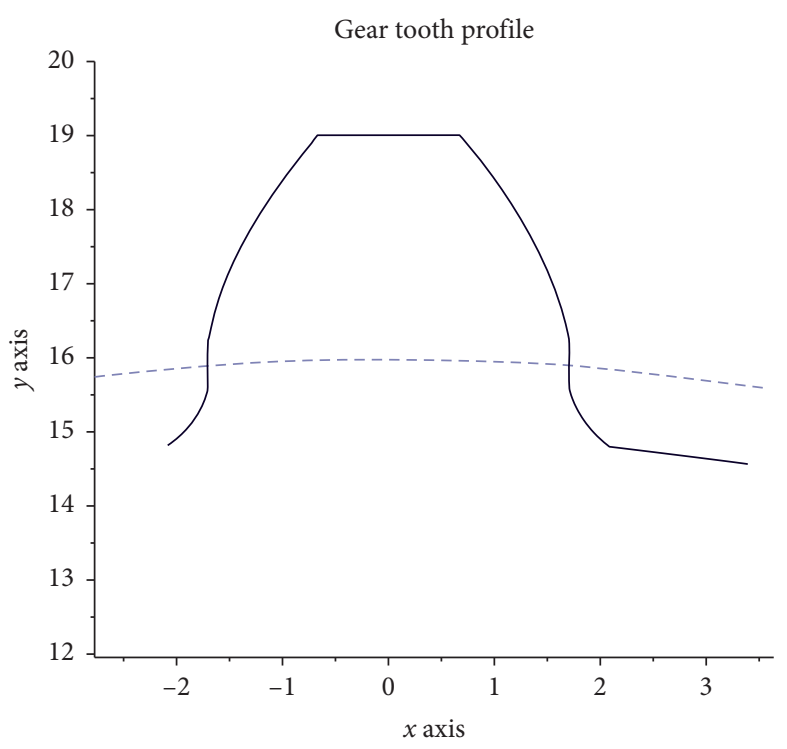

Figure 10: The correct arc.

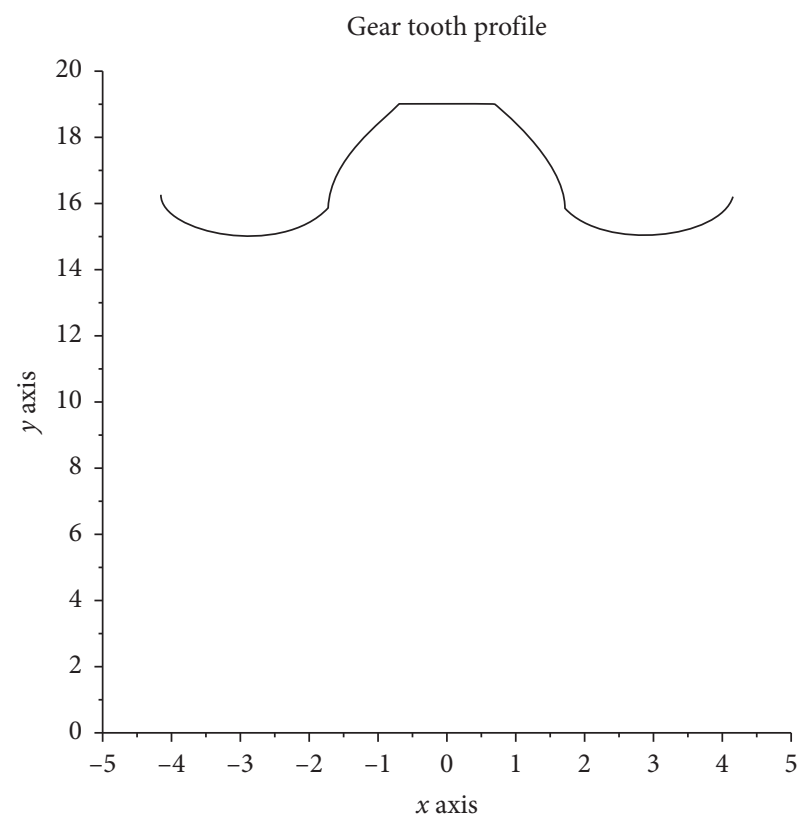

FIgURE 11: The wrong arc.

The negative reciprocal slope is

$$
-\frac{1}{k}=-\frac{\sin \left((\pi / 2 z)+\tan \alpha_{\mathrm{t}}-\alpha_{\mathrm{t}}-\tan \alpha_{\mathrm{y}}+\alpha_{\mathrm{y}}\right)}{\cos \left((\pi / 2 z)+\tan \alpha_{\mathrm{t}}-\alpha_{\mathrm{t}}-\tan \alpha_{\mathrm{y}}+\alpha_{\mathrm{y}}\right)} .
$$

After obtaining the value of the slope, it supposes this situation, that is, the curve below the base circle. Figure 14 shows the detailed analyze of the arc. From Figure 14, point $A$ is the start point and point $B$ is the end point. The negative reciprocal slope can provide the value $\theta$ :

$$
\theta=\arctan \left(-\frac{1}{k}\right) \text {. }
$$




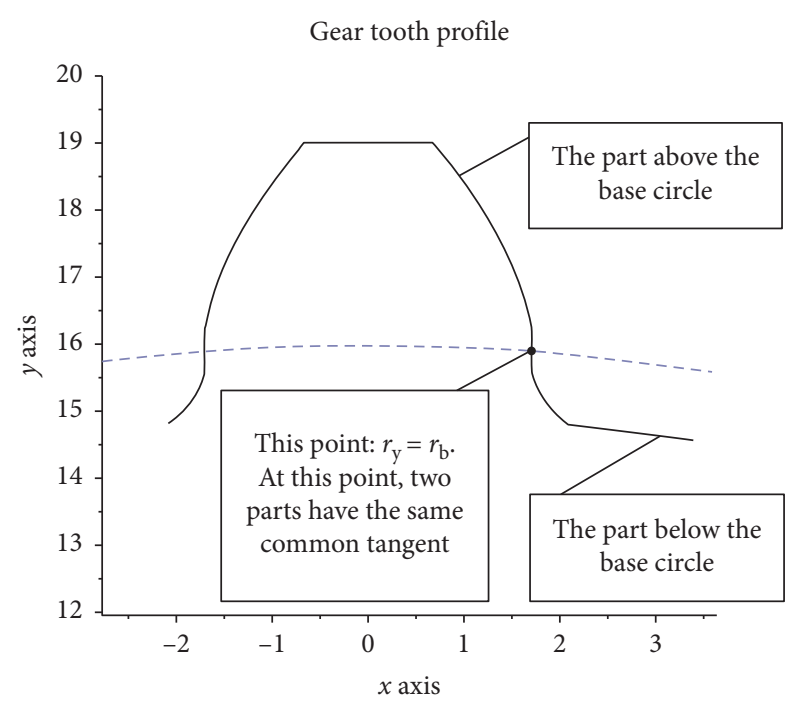

FIgure 12: The analysis of the arc.

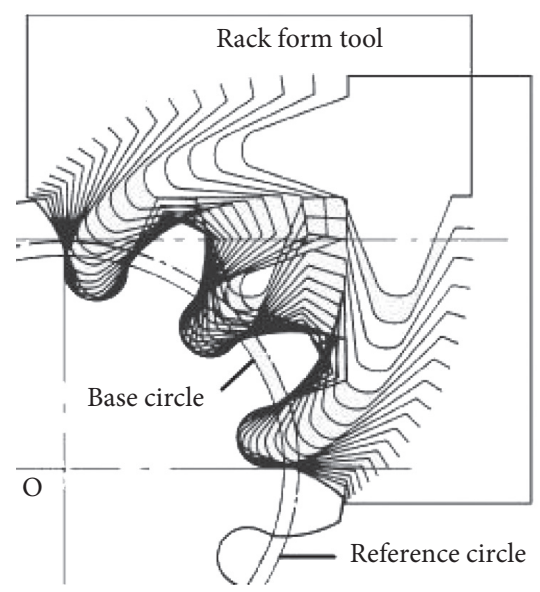

FIGURE 13: The generating method.

So, the next step is to obtain the radius $r$. To get the value $r$, we need to obtain the value of vertical distance $(\mathrm{H})$ between $\mathrm{A}$ and B:

$$
\begin{aligned}
& H=r_{\mathrm{b}}-r_{\mathrm{f}}=1.25 m-\frac{m \times z}{2}\left(1-\cos \alpha_{\mathrm{t}}\right), \\
& H=r+r \times \sin \theta,
\end{aligned}
$$

where $r_{\mathrm{f}}$ is the radius of the tooth circle, $H$ is the difference between $\mathrm{A}$ and $\mathrm{B}$ in $Y$ axis, and $r_{\mathrm{c}}$ is the radius of this circle (A-B).

With equations (17) and (18), we can get the radius of this circle $(\mathrm{A}-\mathrm{B})$ :

$$
\begin{aligned}
& X_{\mathrm{C}}=X_{\mathrm{A}}+r_{\mathrm{c}} \times \cos \theta, \\
& Y_{\mathrm{C}}=Y_{\mathrm{A}}+r_{\mathrm{c}} \times \sin \theta,
\end{aligned}
$$

where $\mathrm{C}$ is the value of $\mathrm{C}$ point in $X$ and $Y$ axis.

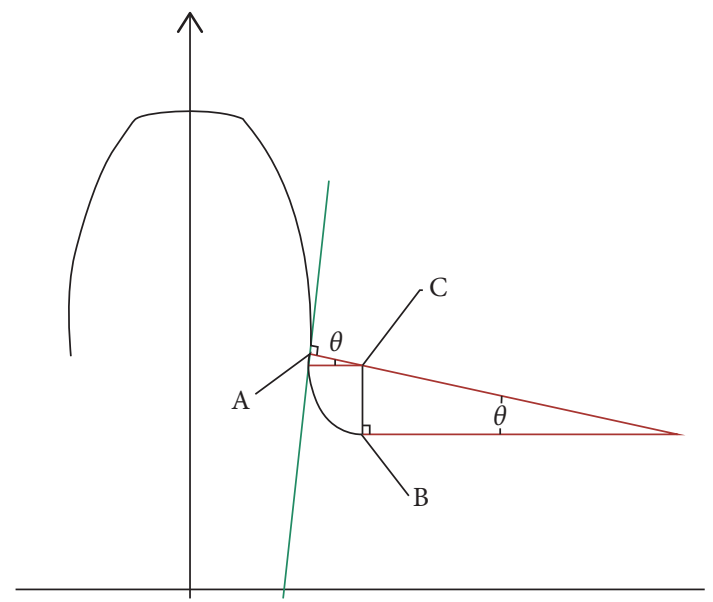

Figure 14: The detailed analysis of the arc.

With equations (19) and (20), we can obtain the center of this circle (A-B).

After that, it is easy to compute the graphic curve in Scilab. And with the radius $r_{\mathrm{f}}$, the whole one tooth of the spur gear can be computed. The whole involute tooth profile is shown in Figure 15.

3.4. Create the Whole Spur Gear. Using the rotation matrix, as shown in equations (21) and (22), we can create the whole spur gear. The whole spur gear is shown in Figure 16:

$$
\begin{aligned}
\theta & =\frac{2 \pi}{z}, \\
M(\theta) & =\left[\begin{array}{cc}
\cos \theta & -\sin \theta \\
\sin \theta & \cos \theta
\end{array}\right] .
\end{aligned}
$$

\section{Practical Application of Parametric Modeling}

4.1. Parameter Modeling Based on Scilab. The parameter modeling method is applicable to the parameterized design in the different circumstances. If there are some changes in the relevant parameter, the model will be changed to a new one.

Here is the flow chart to describe the whole programming procedure, that is, computed by Scilab. Figure 17 is the program flow chart. In order to ensure the optimal design of the tooth profile curve and reduce the processing difficulty, we refer to the value of the processing example provided by the laser-cutting machine. The spur gear has five independent variables, such as module $(m)$, number of teeth $(z)$, clearance coefficient $(c *=0.5)$, pressure angle $\left(\alpha_{\mathrm{t}}=\pi / 9\right)$, and coefficient addendum height $\left(h_{a^{*}}=1\right)$. The spur gear has four dependent variables, such as radius of reference circle $(r=m \times z)$, radius of base circle $\left(r_{\mathrm{b}}=r \times \cos \alpha\right)$, radius of top circle $\left(r_{\mathrm{a}}=r+m\right)$, and dedendum $\left(h_{\mathrm{f}}=1.5 \times m\right)$. 


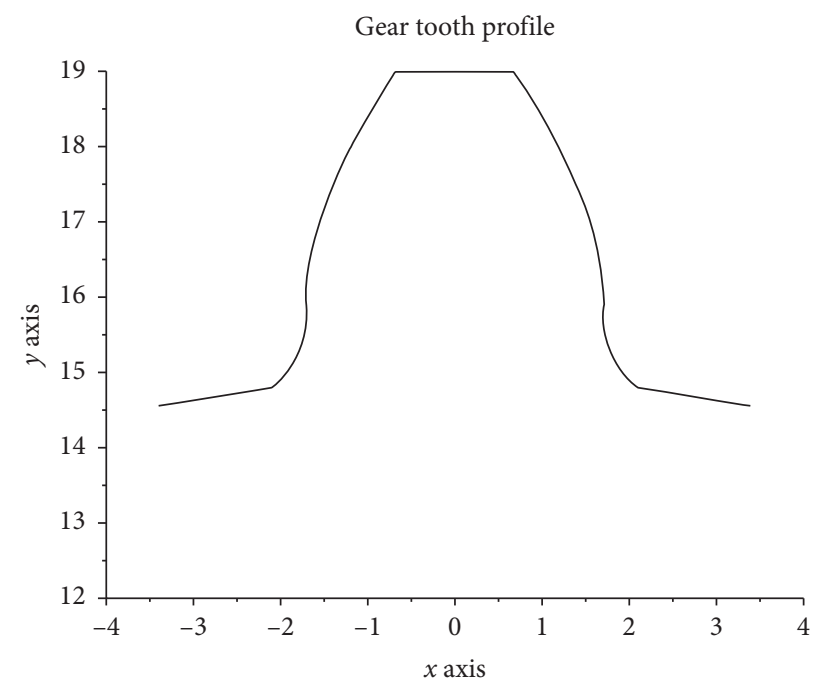

FIgURE 15: The whole involute tooth profile.

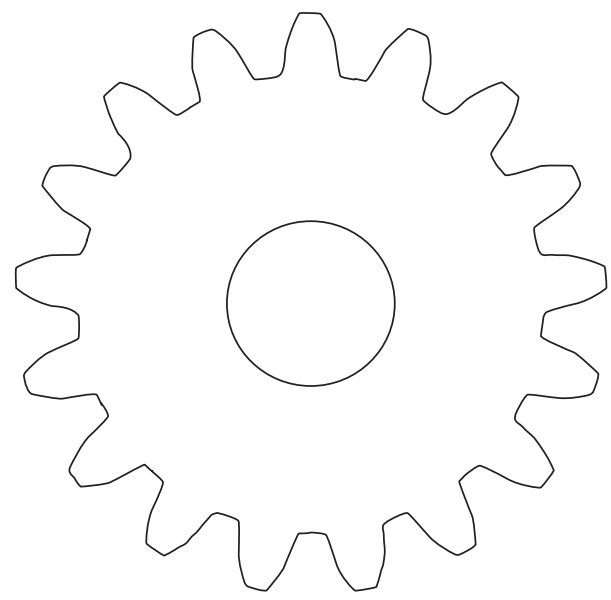

Figure 16: The whole spur gear.

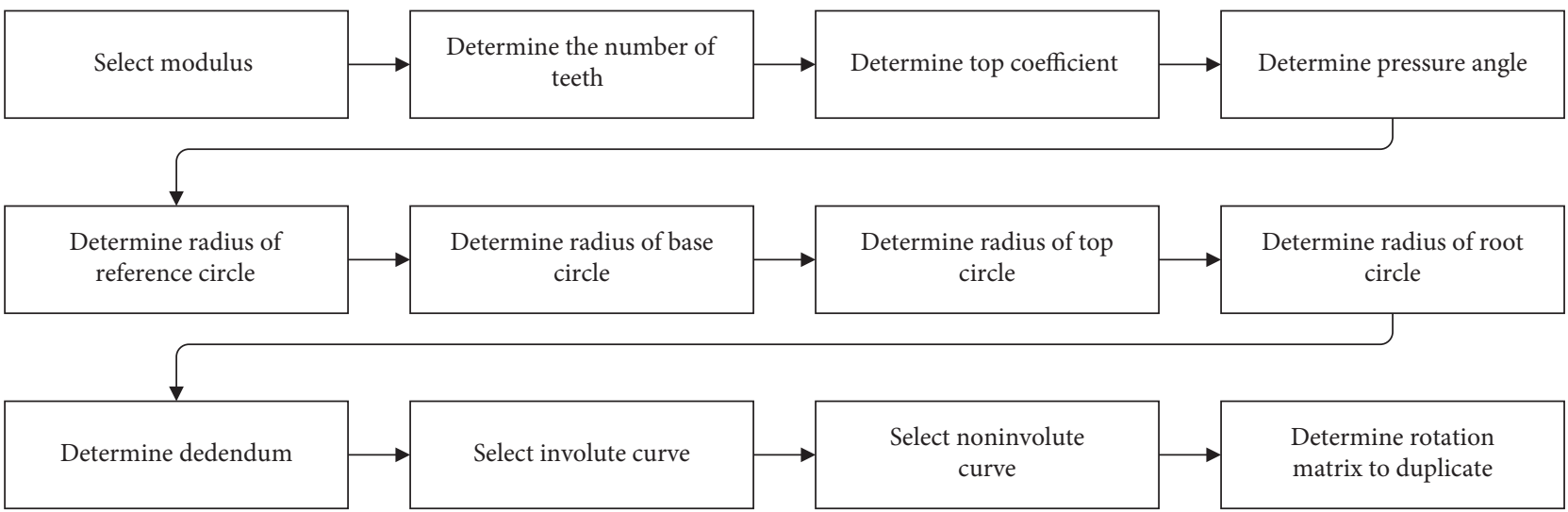

FIGURE 17: The program flow chart.

Because the independent variable's value can be input in the beginning of the program, these four parameters relate to five dependent variables. Secondly, equations (9)-(11) represent the involute curve.
The involute curve program can see Figure 18. In this flow chart, the involute curve is divided into the face in the tooth profile and top land. The variables are assumed as $r_{\mathrm{y}}$. Hence, the one tooth's tooth profile can be represented. We 


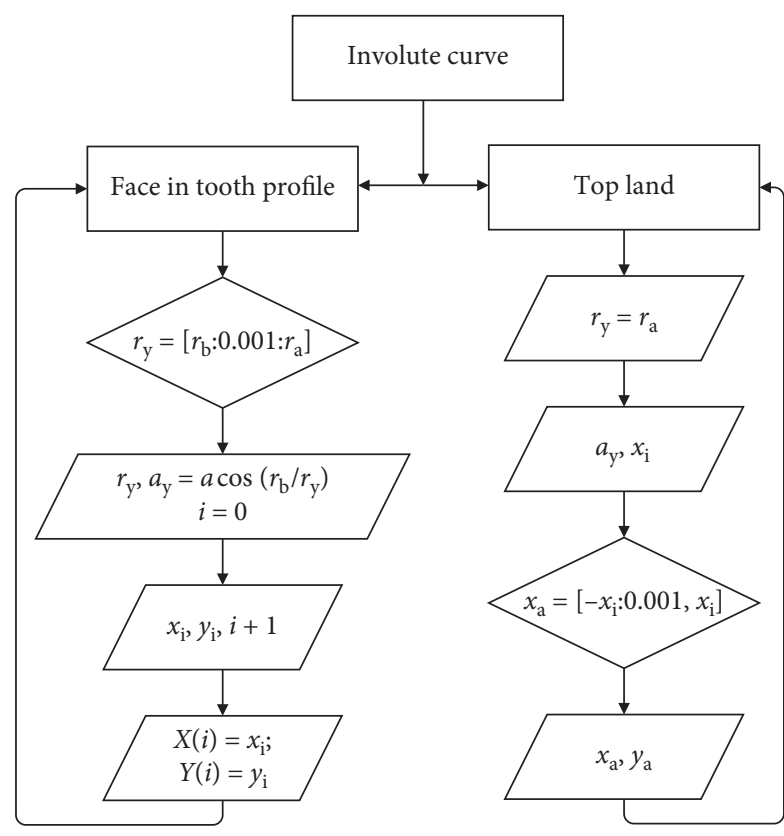

FIgURE 18: The involute curve flow chart.

assume that the range of $r_{\mathrm{y}}$ value is between $r_{\mathrm{b}}$ and $r_{\mathrm{a}}$. Using equations (9) and (10), we can get the coordinates of the curve and present them in the matrix. So, the face in the tooth profile is modeled. And, the top land is the same way.

In the noninvolute curve, a simple arc under the base circle is created. Figure 19 shows the noninvolute curve flow chart. Firstly, it is important to get the value of the center of the arc and the radius of this arc. As shown in Figure 14, with equations (15)-(18), this problem can be solved. Secondly, to create this arc, it should be considered that this arc links the point $\mathrm{A}\left(r_{\mathrm{y}}=r_{\mathrm{b}}\right)$. Besides, the angle of this arc is assumed between $(\pi / 2-\theta)$ and $\pi / 2$. Therefore, it can be represented by an arc that links the tooth profile under the base circle and the root circle.

Using the rotation matrix in the two-dimensional plane, the entire spur gear can be created by duplicating and rotating the above two parts.

This spur gear model is edited by some relevant parameter, such as the radius of reference circle, base circle, module, and the number of teeth. There are different values of these parameters, and the program will output different models.

Figure 20 shows the spur gear in which the number of teeth is 17, and Figure 21 shows the spur gear in which the number of teeth is 23 . Although the value of module is 0.5 , the value of the number of teeth is different. So, two different initial parameters are input in the program, but the program outputs two different spur gears.

Figures 20 and 21 were manufactured by laser-cutting machine, and Figure 22 shows the outcomes.

4.2. Improvement of Spur Gears. When the gear is machined with a rack-type tool, the reference line of the tool is no longer tangent to the reference circle of the gear if it is not installed in a standard, but the tool is moved away from or near the blank's rotation center. This method changes the relative position of the tool and the gear to process the gear is called the modifying method.

By the change to the basic parameters, it is essential to recalculate some relevant values such as tooth thickness, tip circle radius, and dedendum.

Because there is a value named modified coefficient $(x)$, which decides whether a spur gear is the modified gear. If $x=0$, there is no modified spur gear. And the modified coefficient $(x)$ has the minimum value:

$$
x_{\min }=h_{\mathrm{a}}^{*} \frac{\left(z_{\min }-z\right)}{z_{\min }},
$$

where $h_{\mathrm{a}}^{*}$ is the Addendum coefficient $h_{\mathrm{a}}^{*}=1$ and $z_{\min }$ is the minimum number of teeth.

Compared with the transfer of tooth thickness to the base circle (Figure 3), the tooth thickness formula is changed to the following formula:

$$
s_{\text {ty }}=d_{\mathrm{y}}\left(\frac{s_{\text {tref }}}{d_{\text {ref }}}+\operatorname{inv} \alpha_{\mathrm{t}}-\operatorname{inv} \alpha_{\mathrm{y}}\right)+2 x \tan \left(\alpha_{\mathrm{t}}\right) m .
$$

The tip circle radius is changed as follows:

$$
r a=r+\left(h_{\mathrm{a}}^{*}+x\right) m .
$$

Because the base circle has nothing to do with the modified coefficient $(x)$, so it is easily to replace equation (1) by (24) for the involute curve of the modified spur gear. Then, the involute curve in the modified spur gear can be created by the same way.

Besides, equation (11) is replaced by equation (25), and it can be easy to create the top land in the modified spur gear. After that, the involute curve in the modified spur gear can be represented entirely.

\section{The Optimization of the Arc in Noninvolute Profile}

Because the common mathematic equation cannot represent the curve in the noninvolute profile of the spur gear, so it is essential to optimize the above noninvolute profile that the circle arc is assumed.

This section sets an example as Figure 13, and it shows that, the circle arc starts from the point $\mathrm{A}$ and ends at point $\mathrm{B}$. The center and the radius of this arc are key parameters to create this curve. Besides the value of $Y$-axis at point $B$ cannot be above the root circle; otherwise, there is no intersection in the curve of this arc and root circle.

5.1. The Design Parameter. There are some mathematics equations to describe the arc curve. In all parameters, there are three major parameters as the design parameter in this arc optimism, which include $x_{\mathrm{c}}, y_{\mathrm{c}}$, and $r_{\mathrm{c}}$. Furthermore, there is a relational expression according to the center of arc $\left(x_{\mathrm{c}}, y_{\mathrm{c}}\right)$ : 


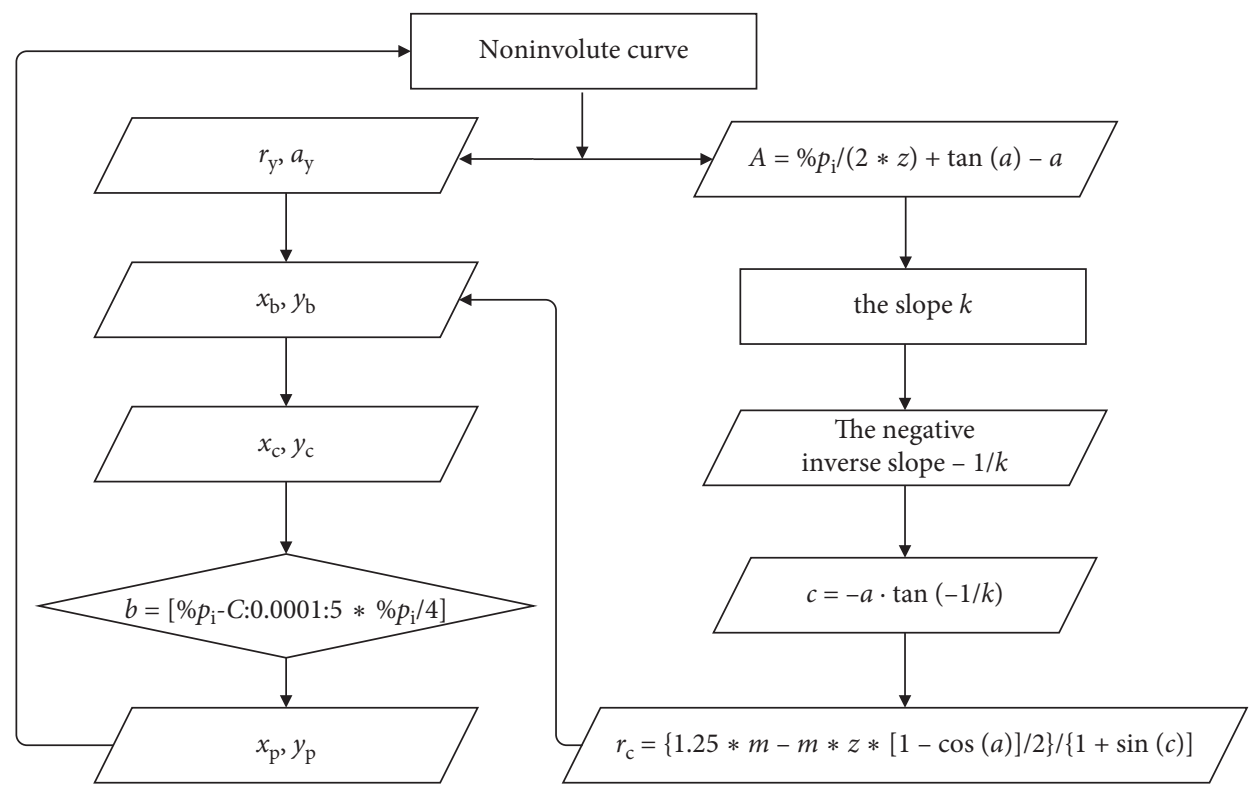

FIgURE 19: The noninvolute curve flow chart.

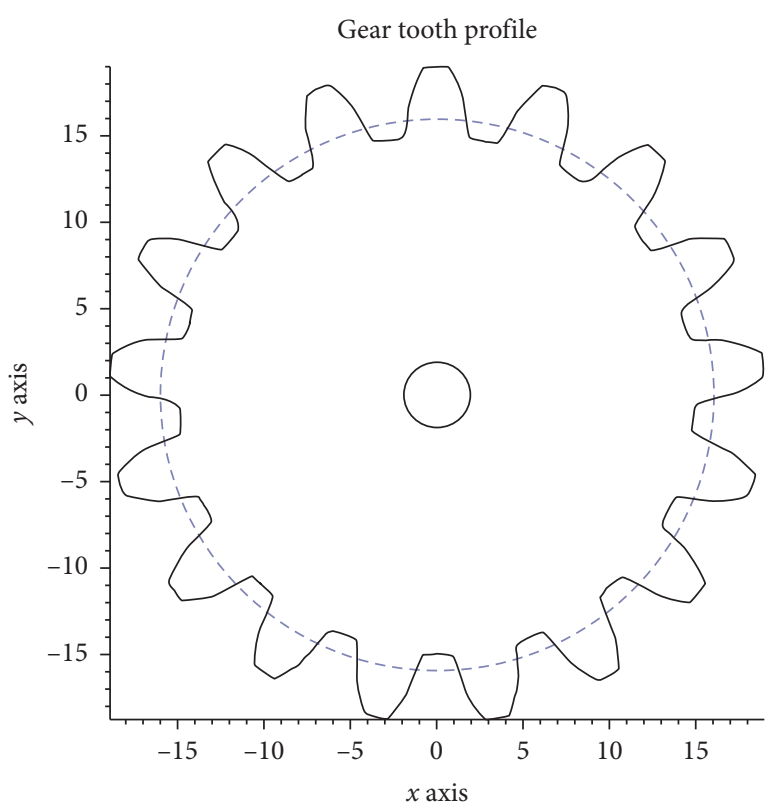

Figure 20: The spur gear $(z=17)$.

$y_{\mathrm{c}}=-\frac{\sin (1 / 2)((2 \pi / z)+\tan \alpha-\partial)}{\cos (1 / 2)((2 \pi / z)+\tan \alpha-a)} x_{\mathrm{c}}+b$,

$b=y_{\mathrm{a}}-\left(-\frac{\sin (1 / 2)((2 \pi / z)+\tan \alpha-\partial)}{\cos (1 / 2)((2 \pi / z)+\tan \alpha-a)}\right) x_{\mathrm{a}}$,

$x_{\mathrm{a}}=r_{\mathrm{a}} \cdot \sin \frac{1}{2}\left(\frac{2 \pi}{z}+\tan \alpha-\alpha-\tan \left(\arccos \frac{r_{\mathrm{b}}}{r_{\mathrm{a}}}\right)+\arccos \frac{r_{\mathrm{b}}}{r_{\mathrm{a}}}\right)$,

$y_{\mathrm{a}}=r_{\mathrm{a}} \cdot \cos \frac{1}{2}\left(\frac{2 \pi}{z}+\tan \alpha-\alpha-\tan \left(\arccos \frac{r_{\mathrm{b}}}{r_{\mathrm{a}}}\right)+\arccos \frac{r_{\mathrm{b}}}{r_{\mathrm{a}}}\right)$.

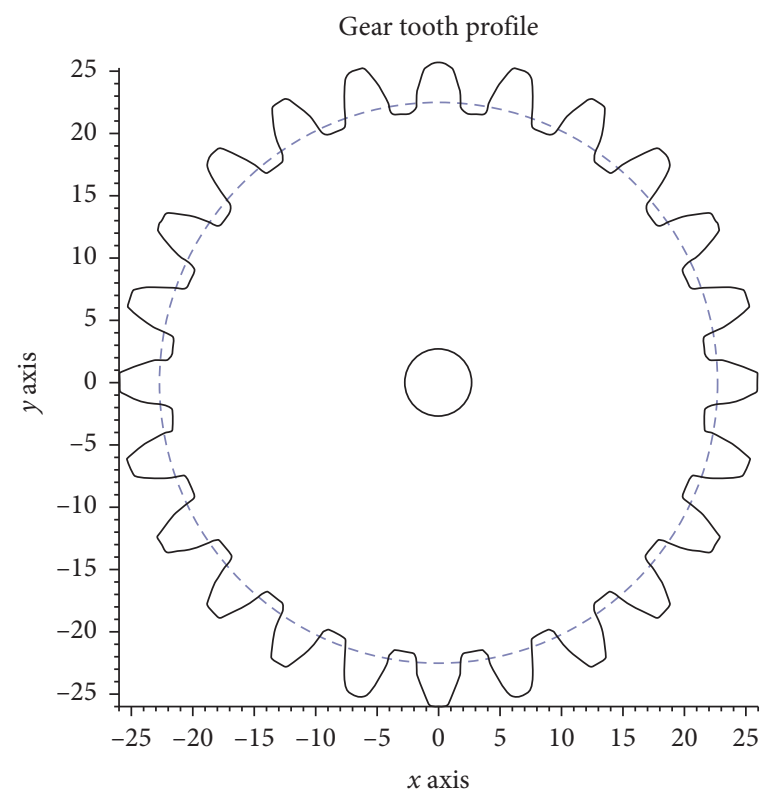

Figure 21: The spur gear $(z=23)$.

In this arc optimism, the design parameter is that

$$
X=\left(x_{c}, y_{c}, r_{c}\right)^{\mathrm{T}}=\left(X_{1}, X_{2}, X_{3}\right)^{\mathrm{T}} \text {. }
$$

5.2. The Objective Function. If the arc curve can get the intersection point with the root circle, it can convert this problem to the difference of the Y coordinate values between the arc segment in point $B$ and the root circle in point $B$ is the minimum value. Figure 20 shows the optimization of the arc. So, the objective function is

$$
\begin{aligned}
\min F(x) & =F\left(x_{1}, x_{2}, x_{3}\right)=\sqrt{r_{\mathrm{f}}^{2}-x_{\mathrm{c}}^{2}}-\left(y_{\mathrm{c}}-r_{\mathrm{c}}\right) \\
& =\sqrt{r_{\mathrm{f}}^{2}-x_{1}^{2}}-x_{2}+x_{3} .
\end{aligned}
$$




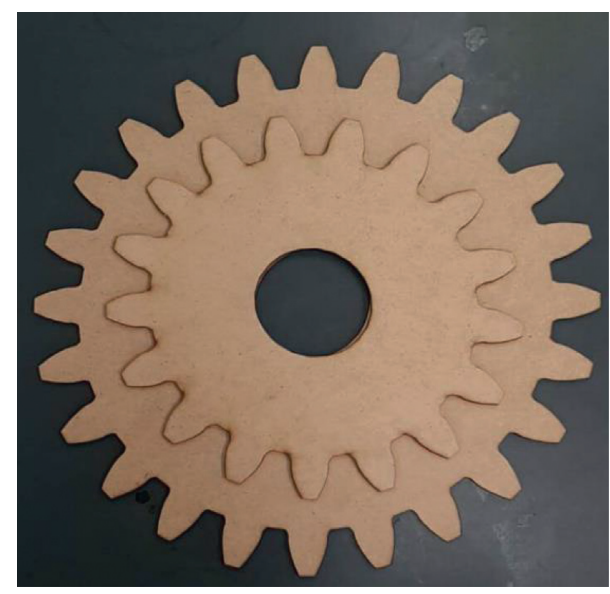

FIgURE 22: The processed goods.

\subsection{The Constraint Conditions}

(1) The constraint of intersection: according to Figure 13, it can be seen that if the arc curve can get the intersection point with the root circle, the radius of this arc should be equal or greater than tooth dedendum. So,

$$
\begin{aligned}
r_{\mathrm{c}} & \geq h_{\mathrm{f}}, \\
h_{\mathrm{f}} & =\left(h_{\mathrm{a}}^{*}+c^{*}\right) m, \\
r_{\mathrm{c}}-h_{\mathrm{f}} & \geq 0 .
\end{aligned}
$$

(2) The constraint of center of arc: first of all, the $X$ coordinate value of this arc center must be between two tooth profiles; furthermore, the center of this arc must be in the linear line $k_{1}$. So,

$$
\begin{aligned}
x_{\mathrm{a}} \leq & x_{\mathrm{c}} \leq \frac{x_{\mathrm{a}}+x_{\mathrm{a} 1}}{2}, \\
\frac{x_{\mathrm{a}}+x_{\mathrm{a} 1}}{2}-x_{\mathrm{c}} \geq 0 & \\
x_{\mathrm{c}}-x_{\mathrm{a}} \geq 0 & , \\
y_{\mathrm{c}}= & {\left[-\frac{\sin (1 / 2)((2 \pi / z)+\tan \alpha-\partial)}{\cos (1 / 2)((2 \pi / z)+\tan \alpha-a)}\right] x_{\mathrm{c}}+y_{\mathrm{a}} } \\
& +\left(-\frac{\sin (1 / 2)((2 \pi / z)+\tan \alpha-\partial)}{\cos (1 / 2)((2 \pi / z)+\tan \alpha-a)}\right) x_{\mathrm{a}} .
\end{aligned}
$$

5.4. The Optimization Method Choice. In the design of spur gear transmission, optimization methods are always chosen composite or penalty function. But they have their own shortcomings, such as composite, because it is a direct method of optimality, and it is not applicable to the equation, so it is not very generic; and the penalty function method, although it overcomes the shortcomings of composite, has to increase the complexity of the optimization design. As a result, Powell is chosen as a more concise one.

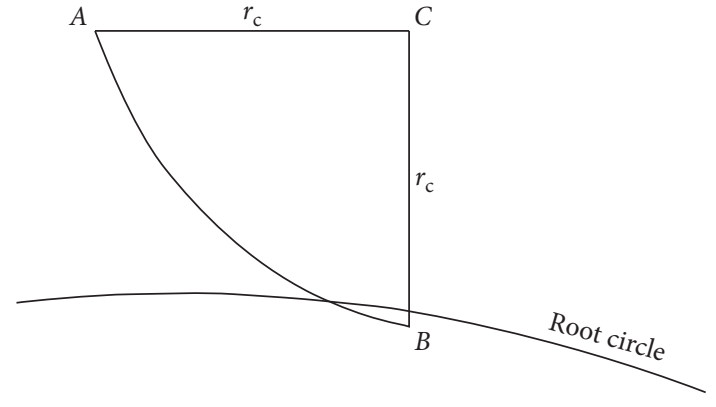

Figure 23: The optimization of the arc.

The best advantage of the Powell law is that you do not need to compute the gradient of the target function. It processes the multidimensional problem into a series of single-dimensional problems in the search. It also avoids the possibility that the coordinates rotation method might not show the ideal direction. It uses the common wheel direction for the search direction, and the search efficiency is very high.

5.5. The Analysis of the Optimization Outcome. The outcome of the optimization after the program debugged is that

$$
X=\left(x_{c}, y_{c}, r_{c}\right)^{\mathrm{T}}=[2.2764889,11.805171,0.9990810]^{\mathrm{T}},
$$

$\min F(X)=0.467285$.

In Figure 23, there is a little space between the arc in the noninvolute profile and the root circle at point $B$, which means there are two points of intersection in these two curves. Furthermore, these two points of intersection, respectively, are the end of the arc in the noninvolute profile away from point $B$ and the start of the arc in the noninvolute profile away from point B. After the optimization, this spur gear can be more precise.

\section{Conclusion}

Spur gear is one of transmission gears, with high transmission efficiency, smooth transmission, and other advantages. Based on the knowledge of the gear theory, this article computed the program to characterize the gear characteristics and used the SCILAB software to complete the spur gear graphic. The key to this subject is to design the involute part in the gear tooth profile precisely. A mathematical model for the parametric tooth profile of spur gears is put forward in this article, and it provides a new mean to model the standard spur gears or modified spur gears. Besides, the optimization in the noninvolute curve is unique comparing other modeling methods. This model improves efficiency and accuracy of spur gear modeling.

The research direction focuses in the links of parametric modeling and practical engineering problems. Using Scilab, it will create simply spur gear parametric modeling, then improve the model of the modified gear, and optimize the noninvolute part of the arc. Using the mathematics modeling, if it provides any more on the spur gear parameters 
input, the output of the spur gear model can be more accurate.

\section{Data Availability}

The data used to support the findings of this study are available from the corresponding author upon request.

\section{Conflicts of Interest}

The authors declare no potential conflicts of interest with respect to the research, authorship, and/or publication of this article.

\section{Acknowledgments}

This work was supported by the National Training Program of Innovation and Entrepreneurship for Undergraduates (Grant no. 201911413045), Cross Training Program of High-Level Talents in Beijing University (Grant no. 2019114132316), National Fundamental Research Funds for the Central Universities of China (Grant no. 2014YJ02), National Undergraduate Innovation and Entrepreneurship Training Program (Grant no. 201611413086), and Beijing College Students Innovation Training Project (Grant no. K201504024).

\section{References}

[1] W. B. Zhu, D. Yang, Y. Gan, and L. Chen, "Tooth profile design and meshing backlash optimization of circular arc tooth profile harmonic gear," Machine Design, vol. 36, no. 2, pp. 32-39, 2019.

[2] D. Liang, J. Wang, and K. Zhang, "Optimum design of arc bevel gear for new energy vehicle reducer based on penalty function," Journal of Shenyang University (Natural Science Edition), vol. 30, no. 6, pp. 507-510, 2018.

[3] V. Spitas and C. Spitas, "Optimizing involute gear design for maximum bending strength and equivalent pitting resistance," Proceedings of the Institution of Mechanical Engineers, Part C: Journal of Mechanical Engineering Science, vol. 221, no. 4, pp. 479-488, 2007.

[4] C. Jia, Z. D. Fang, X. J. Zhang, and X. H. Yang, "Optimum design and analysis of helical gear tooth profile modification," Journal of Huazhong University of Science and Technology (Natural Science Edition), vol. 46, no. 5, pp. 66-71, 2018.

[5] S. Padmanabhan, V. S. Raman, P. Asokan, S. Arunachalam, and T. Page, "Design optimisation of bevel gear pair," International Journal of Design Engineering, vol. 4, no. 4, pp. 364-393, 2011.

[6] M. B. Sánchez, M. Pleguezuelos, and J. I. Pedrero, "Influence of profile modifications on meshing stiffness, load sharing, and transmission error of involute spur gears," Mechanism and Machine Theory, vol. 139, pp. 506-525, 2019.

[7] F. L. Litvin and A. Fuentes, Gear Geometry and Applied Theory, Cambridge University Press, New York, NY, USA, Second edition, 2004.

[8] V. Zelený, I. Linkeová, J. Sýkora, and P. Skalník, "Mathematical approach to evaluate involute gear profile and helix deviations without using special gear software," Mechanism and Machine Theory, vol. 135, pp. 150-164, 2019.

[9] Z. Yuan, Z. L. Sun, and Y. Guo, "Optimum design of tooth profile repair curve of spur gear," Mechanical Transmission, vol. 34, no. 5, pp. 1-4, 2010.
[10] Z. M. Fan and G. H. Zhang, "Gear profile parameter optimization and hob design of double involute gear," Mechanical Design, vol. 12, pp. 37-39, 2002.

[11] T. Y. Guo, Y. C. Liang, and W. Y. Li, "Optimum design of tooth root transition curve shape of involute gear," $M e$ chanical Transmission, vol. S1, pp. 21-22, 1996.

[12] H. Tian, F. Wu, and Y. J. Gong, "Gear tooth profile reconstruction via geometrically compensated laser triangulation measurements," Sensors (Basel, Switzerland), vol. 19, no. 7, 2019.

[13] G. Figliolini, H. Stachel, and J. Angeles, "Kinematic properties of planar and spherical logarithmic spirals: applications to the synthesis of involute tooth profiles," Mechanism and Machine Theory, vol. 136, 2019.

[14] D. Ma, Z. Ye, and H. Yang, "Tooth surface reconstruction and tooth profile geometric analysis of circular arc tooth trace cylindrical gears," Transactions of Famena, vol. 43, no. 1, pp. 29-44, 2019.

[15] R. Woodbury, Elements of Parametric Design, Routledge, Abingdon, UK, 2010.

[16] W. Jabi, Parametric Design for Architecture, Laurence King, London, UK, 2013.

[17] C. M. Wen, H. Li, and K. Wen, "Helical gear modeling based on SolidWorks in accordance with processing law," Mechanical Engineer, vol. 8, pp. 202-203, 2016.

[18] P. P. Liu and D. H. Qian, "Research on three-dimensional accurate modeling of involute gear based on optimum design theory and UG platform," Coal Mine Machinery, vol. 32, no. 9, pp. 227-229, 2011.

[19] Q. Li, J. F. Jiang, Y. L. Chang, and L. T. Wang, "Modeling optimization and machining detection of logarithmic spiral bevel gears," Tool Technology, vol. 51, no. 3, pp. 51-54, 2017.

[20] Z. P. Li and Y. L. Jia, "Optimal design and motion simulation analysis of involute gear," Manufacturing Automation, vol. 32, no. 3, pp. 169-171, 2010.

[21] G. F. Tao, B. W. Wang, X. Y. Zhai, and L. S. Zou, "Multiobjective optimization design of gear strength for a new type of transmission structure with few teeth difference," Journal of Guilin Institute of Aerospace Technology, vol. 24, no. 1, pp. 25-30, 2019.

[22] A. Y. Wang and S. Y. Ma, "Modeling and design of end face helical gear based on CORO," Small Internal Combustion Engine and Vehicle Technology, vol. 47, no. 3, pp. 38-40, 2018.

[23] J. H. Li and F. P. Yao, "Optimizing the profile of spur bevel gear based on MATLAB," Manufacturing Technology and Machine Tools, vol. 4, pp. 133-136, 2008.

[24] M. Dolen, H. Kaplan, and A. Seireg, "Discrete parameternonlinear constrained optimisation of a gear train using genetic algorithms," International Journal of Computer Applications in Technology, vol. 24, no. 2, pp. 110-121, 2005.

[25] Y. Wang, S. Ren, and Y. Li, "Design and manufacturing of a novel high contact ratio internal gear with a circular arc contact path," International Journal of Mechanical Sciences, vol. 153-154, pp. 143-153, 2019.

[26] W. Y. Lin, K. M. Hsiao, and J. Y. Ke, "Optimum design of involute tooth profiles for $\mathrm{K}-\mathrm{H}-\mathrm{V}$ planetary drives with small teeth number differences," Journal of Advanced Mechanical Design Systems and Manufacturing, vol. 13, no. 1, 2019.

[27] V. A. Spitas, T. N. Costopoulos, and C. A. Spitas, "Optimum gear tooth geometry for minimum fillet stress using BEM and experimental verification with photoelasticity," Journal of Mechanical Design, vol. 128, no. 5, pp. 11591164, 2006. 
[28] D. Liang, B. Chen, and Y. Gao, "Hobbing manufacturing of new type of involute-helix gears for wind turbine gearbox," International Journal of Precision Engineering and Manufacturing-Green Technology, vol. 6, no. 2, pp. 305-313, 2019.

[29] C. Wang, Z. D. Fang, L. L. Guo, and H. T. Jia, "Optimum design and experimental study on profile modification of herringbone gear," Journal of Northwest Polytechnic University, vol. 28, no. 2, pp. 224-227, 2010.

[30] G. S. Feng, Z. F. Xie, and M. Zhou, "Geometric design and analysis of face-gear drive with involute helical pinion," Mechanism and Machine Theory, vol. 134, 2019. 